\title{
Decision Support in Supply Chain Management for Disaster Relief in Somalia*
}

\author{
E. van Wyk, V.S.S. Yadavalli, and H. Carstens \\ Department of Industrial and Systems Engineering \\ University of Pretoria \\ South Africa \\ \{Estelle.vanwyk, Sarma.yadavalli\}@up.ac.za, \\ Hermancarstens@atesouthafrica.com
}

\begin{abstract}
Somalia, a country situated in Eastern Africa has been struggling between rival warlords and an inability to deal with famine. Diseases have resulted to the deaths of up to millions of people. According to a New York Times article on 25 November 2011, Somalia has become a suffering and failed state. The inadequate infrastructure and poorly planned logistics of Somalia may lead to the destruction of the country.

To address these concerns, it is necessary that humanitarian aid is prepositioned to provide victims with sufficient relief. This chapter addresses some of the issues in supply chain management with the trade-off between stockpile cost and shortage cost by using pre-emptive multi-objective programming. The proposed criteria of the model are described. This is followed by a case study based on Somalia, illustrating the functionality of the model.
\end{abstract}

\section{Introduction}

\subsection{The Importance of Disaster Management}

The severe effects of natural and man-made disasters are made obvious by observing any media source. On 13 November 2011, Agence France-Presse (AFP) stated that United Nations (UN) climate scientists forecast the likelihood of increasing heat waves in Southern Europe [1]. In addition, North Africa will be more susceptible to droughts, and rising seas will cause storm surges in small island states. According to the AFP, peer reviewed scientific journals are claiming that the impact of disasters have a $90 \%$ probability of becoming unbearable over time [1]. A summary for policy makers drafted by the AFP claims:

"Global warming will create weather on steroids."

It is feared that in the future, entire communities could be obliterated by a single disaster. The living conditions of communities will degrade as disasters increase in

A modified version of this paper was presented at ICMIE conference in Singapore, February 2012 
frequency and/or severity, which in turn will cause an increase in permanent migration and present more pressures in areas of relocation, leading to a greater need for disaster management.

Tomasini and Wassenhove [2] define disaster management as the result of a long and structured process of strategic process design, ultimately resulting in successful execution. Disaster management can be divided into four phases: mitigation, preparedness, response and recovery. These phases are known collectively as the disaster operations life cycle. Mitigation is the application of measures that either prevent the onset of a disaster or reduce the impact should a disaster occur. Preparedness relates to the community's ability to respond when a disaster occurs; response refers to the employment of resources and emergency procedures as guided by plans to preserve life, property, and the governing structure of the community. Finally, recovery involves actions taken to stabilize the community subsequent to the immediate impact of a disaster [2]. The disaster cycle is illustrated in Figure $1^{1}$.

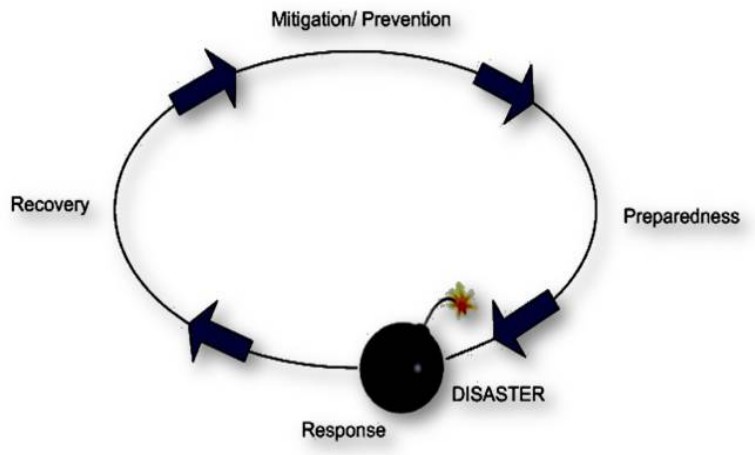

Fig. 1. The disaster cycle

Tomasini and Wassenhove [2] emphasise that the first 72 hours after a disaster has occurred are crucial in order to save the maximum amount of human lives. Saving lives, however, relies on the correct quantity and types of aid supplies, which would be a fairly effortless resolution, if all disaster effects could be predicted. Arminas [4] suitably describes this predicament as follows:

“...purchasing and logistics for major disaster relief is like having a client from hell: You never know beforehand what they want, when they want it, how much they want and even where they want it sent."

As a consequence of this complexity, it is vital that relief supplies be pre-positioned to improve emergency response times. This forms part of the preparedness phase in the disaster operations life cycle. Demand for aid supplies will vary in type and quantity depending on the specific disaster and the level of destruction it causes. These supplies

\footnotetext{
${ }^{1}$ Adapted from Ciottone [3].
} 
must meet the immediate needs of those affected and will include items such as food, medicine, tents, sanitation equipment, tools and related necessities [5].

Considering the problem of preparing for a disaster, Somalia is suffering severely due to poverty, famine and the strongholds of the terrorist group, al-Shabaab. Somalia is in urgent need of humanitarian aid and is therefore considered as the case study for this work. The existing disasters for Somalia are identified as well as the associated inventory which would be necessary for survival.

\subsection{Somalia as a Case Study}

Since the spring in 2011, Somalia experienced a drought which is considered to be the worst in 60 years [6]. The country has suffered from crop failure, an extreme rise in food prices, as well as the grip of al-Shabaab on central and South Somalia. These factors have forced the United Nations (UN) to declare famine in six areas of Somalia. These areas have currently been reduced to three areas due to the assistance of humanitarian organizations over the past few years. The increase in assistance, however, has been insufficient as there are still 3.7 million victims in need of emergency assistance and 250,000 in danger of dying. The famine has compelled thousands of victims to move to overfull refugee camps in Ethiopia, Kenya, and Djibouti, while other victims have fled to Internally Displaced Persons camps in Mogadishu [6]. The United States, UN, and international humanitarian organizations have been trying to address the immediate needs of the victims in Somalia [6].

The unfortunate circumstances leaves Somalia in need of a more permanent solution, i.e., more research should be done so that adequate solutions are obtained and facilities should be pre-positioned in disaster areas with a sufficient supply of relief aid. This study is based on the formulation of mathematical modeling as a means to determine the quantities of aid supplies at a pre-positioning facility within Somalia. Preemptive multi-objective programming is employed to ensure that areas will be supplied with immediate disaster relief.

The remainder of this chapter is structured as follows: A literature review addresses the problem variants associated with disaster relief and existing models that have been developed to accommodate these areas. The research methodology presents the formulated model. The model results and the findings are then discussed, followed by some conclusions and future research developments.

\section{Literature Review}

\subsection{Problem Variants}

Considerable literature has addressed the management of disaster relief organizations. Much of this deals with the social and organizational implications of responding to disasters in many parts of the world, including countries with poor infrastructure and/or may be involved in hostilities. Blecken et al. [7] state that even though research contributions to supply chain management in the context of humanitarian 
operations have increased, a gap remains when considering pre-positioning in countries such as Somalia. Being prepared for a disaster requires the knowledge of knowing when or where an event will take place, how many people will be affected and what supplies will be required. Despite the progress that disaster planning, mitigation and new management systems have made, the need for relief, specifically in underdeveloped countries, still remains [5]. Improving disaster relief planning and management is a continuous process.

Due to the unpredictable nature of a disaster, disaster management is a process that cannot be comprehensively controlled. Altay and Green [8] explain that even though it is known that response to disasters requires effective planning, it is crucial to leave room for improvisation in order to deal with the unusual challenges that manifest. Hills [9] approvingly states that the phrase disaster management implies a degree of control, which rarely exists in disaster cases. It is for this reason that Standard Management Methods used in industry may not always apply directly to disaster situations [9].

Rawls and Turnquist [10] raise an added concern, namely that the capacities of resource providers are the key components in managing response efforts subsequent to disaster events, but that only a small amount of research has been conducted on the planning and distribution of aid supplies kept in inventory at prepositioned facilities. In addition, Duran et al. [11] maintain that an important element to take into account when considering stock pre-positioning is that facilities should always have sufficient inventory to satisfy demand. It should also be considered that stored aid supplies may be destroyed during a disaster event [11]. The pre-positioned stock should thus meet the needs of a disrupted region by taking the effect of the disaster into consideration [12].

Any shortcomings may result in serious consequences for victims of disasters and could mean the difference between life and death [2]. The public thus expects "perfect orders" and that humanitarian supply chains need to be more adaptable and agile towards the changing needs of disaster victims [2]. This need demands effective methods to improve disaster preparedness.

\subsection{Existing Solutions}

The majority of favourable solutions to disaster management problems are supported by mathematical methods such as operations research [13]. This approach is an appropriate tool for planning the preparedness, response and recovery phases of disaster management, due to its ability to handle uncertainty by means of probabilistic scenarios which represent disasters and their outcomes $[14,15,16,17]$.

Very few journal articles address logistical problems that are related to humanitarian relief. Rawls and Turnquist [10] present a two-stage Stochastic Mixed Integer Program(SMIP) that provides an emergency response pre-positioning strategy for disaster threats. The algorithm is formulated as a heuristic algorithm. The model considers uncertainty in demand for stocked supplies but also includes the uncertainty regarding transportation network availability after an event. A stochastic inventory control model is developed by Beamon and Kotleba [18] in the form of $\left(\mathrm{Q}_{1} ; \mathrm{Q}_{2} ; \mathrm{r}_{1} ; \mathrm{r}_{2}\right)$. The model approach is to use optimal order quantities and re-order points to determine inventory for a pre-positioned warehouse responding to a complex humanitarian 
emergency, including the exceedingly variable demand of the warehouse supply items [18]. The model allows for two types of order lot sizes: $Q_{1}$ for a regular order and $Q_{2}$ for an urgent order. $Q_{1}$ is ordered when the inventory reaches level $r_{1}$ and $Q_{2}$ is ordered when the inventory level reaches $r_{2}$, where $r_{1}>r_{2}$.

A Markovian process is also used to solve the demand distribution of inventory. This idea is initiated by Karlin and Fabens [19], claiming that if each demand state is defined by different numbers, a base stock type inventory policy can be obtained. Taskin and Lodree [20] use stochastic programming to determine an optimal order policy so that the demand in each pre-hurricane season period is met, and reserve supplies are stored for the ensuing hurricane season, in a cost-effective way.

Bryson et al. [12] use optimal and heuristic approaches to solve a number of hypothetical problems. Mixed integer programming is applied to establish the disaster recovery capability of an organisation. The aim of the model is to determine the resources that should be used in order to maximise the total expected value of the recovery capability. The use of mathematical modelling provides an appropriate decision support tool for the successful development of a Disaster Recovery Plan (DRP). This model provides a generic approach which considers different types of resources required to satisfy demand induced by any relevant disaster.

Various models have been developed and applied to the SADC countries [13,20]. VanWyk et al. [13] apply a stochastic inventory model to the SADC countries to obtain the quantities of aid supplies to keep at an acceptable minimum cost. Van Wyk et al. [22] developed a mixed integer decision model which selects sub-plans to supply a country with immediate disaster relief. In addition, a Euclidean Distance Algorithm was formulated to determine the most similar case when compared to a target case disaster [22].

The research done for disaster management problems and specifically the SADC applications, provide useful methods, but only limited research considers case studies applicable to developing countries. This research is aimed at focusing on the capacity required to ensure that a sufficient area within Somalia is covered by a pre-positioning facility. It is therefore a good starting point to develop an innovative model to determine the capacity required to ensure that a sufficient area within Somalia is covered by the pre-positioned facility.

\subsection{Preemptive Multiobjective Programming}

Rardin [23] explains that although practical problems almost always involve more than one measure of solution merit, many can be modelled quite satisfactorily with a single cost or profit objective. Other criteria are either presented as constraints or weighted in a composite objective function to produce a model efficient enough for productive analysis. Many applications such as those in disaster management must be treated as multiobjective. When goals cannot be reduced to a similar scale of cost or benefit, trade-offs have to be addressed. To obtain useful results from such a problem, the multiobjective model must be reduced to a sequence of single objective optimizations [23]. This leads to preemptive multiobjective optimization by considering 
objectives one at a time. The most important objective is optimized subject to a requirement that the first has achieved its optimal value; and so on [23].

The preemptive approach to multiobjective optimization is that it results in solutions that cannot be improved in one objective without degrading another. If each stage of the preemptive optimization yields a single-objective optimum, the final solution is an efficient point of the full multi-objective model. The preemptive process uses one objective function at a time to improve one without worsening others. At the completion of this process, no further improvement is possible. As usual, infeasible and unbounded cases can produce complications, but the typical outcome is an efficient point [23].

\section{$3 \quad$ Research Methodology}

\subsection{Preemptive Optimization}

Humanitarian relief organizations aim to provide relief for as many disaster victims as possible, subject to limited funding. It is therefore useful to consider a model that helps the decision-maker with inventory decisions at the lowest possible cost. The notation of the preemptive model [6] for Somalia is addressed below:

$x_{i k} \triangleq\left\{\begin{array}{l}1 \text { if aid supply } \mathrm{i} \text { is required for disaster } \mathrm{k} \\ 0 \text { otherwise }\end{array}\right.$

$q_{k} \triangleq$ The probability that disaster $k$ will occur

$n_{k} \triangleq \quad$ The number of people affected by disaster $k$

$c_{i} \triangleq$ The unit cost of aid supply $i$

$h_{i} \triangleq \quad$ The holding cost of supply $i$

$s_{i} \triangleq \quad$ The number of people affected if supply $i$ is not available

$u_{i} \triangleq \quad$ The number of people affected if supply $i$ is not available

$v_{i} \triangleq \quad$ The number of aid supply $i$ in excess

$Q_{i} \triangleq \quad$ The number of aid supply $i$ required

The objective functions have been formulated as follows:

$$
\begin{aligned}
& \min Z_{1}=\sum_{i=1}^{I} Q_{i} c_{i}+h_{i} v_{i} \\
& \min Z_{2}=\sum_{i=1}^{I} s_{i} u_{i}
\end{aligned}
$$

s.t.

$$
Q_{i}-v_{i}+u_{i}=\sum_{k=1}^{K} \frac{x_{k i} n_{k} q_{k}}{s_{i}}, i \in I
$$




$$
Q_{i}, v_{i}, u_{i} \geq 0
$$

Objective function (1) minimizes the overall cost of holding excess aid supplies. Objection function (2), minimizes the shortage cost (number of lives affected) of not having an aid supply. Constraint (3) guarantees that the number of aid supplies required for a specific disaster corresponds with the expected demand of a scenario, while taking excess inventory and shortages into consideration. Constraint (4) ensures that decision variables $Q_{i}, v_{i}$ and $u_{i}$ remain greater or equal to 0 . It is assumed that no excess inventory is present during the first usage of the model.

\subsection{Data Gathering}

Predicting a disaster is challenging, and in most cases impossible. However, a probability can be determined to pre-determine the likelihood of such an event. The approach used to determine these estimates was to observe the number of times the identical disasters have occurred in Somalia in the past 30 years. We use data from the Emergency Disaster Database (EM-DAT) as provided by the Centre for Research on the Epidemiology of Disasters (CRED) [24]. In this database, an event qualifies as a disaster if at least one of the following criteria are fulfilled: 10 or more people are reported killed; 100 or more people are reported affected, injured and/or homeless; there has been a declaration of a state of emergency; or there has been a call for international assistance. We measure the severity of a disaster in Somalia by the number of people affected.

The repetition of occurrences of each disaster is then divided by the overall total of Somalia disasters, giving the result of $q_{k}$ of each disaster. The parameter $n_{k}$, represents the estimated number of victims likely to be affected by a disaster in its worst magnitude. Therefore, if a drought occurs, it is most likely that the entire population (100\%) may be affected. These values are multiplied by the total population of an area to give an indication of the total victims affected.

Holding cost comprises the cost of carrying one unit of inventory for one time period, and usually indicates storage and insurance cost, taxes on inventory, labor cost, and cost of spoilage, theft, or obsolescence [25]. However, the inventory carrying cost will vary according to each individual warehouse, but for testing purposes it is assumed that inventory carrying cost equals $25 \%$ of product value per annum [13]. The shortage cost represents the amount of people who will be affected if an aid supply is not available during and after the disaster event.

The preemptive optimization model performs multi-objective optimization by first optimizing objective function (1), i.e., the cost of holding an aid supply. Objective function (2), i.e., the cost of the total shortages, is optimized subject to the requirement that 1 has achieved its optimal value [23].

\section{$4 \quad$ Results and Findings}

The model was solved to construct four efficient frontier curves, each representing a category. The efficient frontier indicates the efficient points when considering the 
holding and shortage cost for each category. The efficient points and the efficient frontier assist to characterize "best" feasible solutions in multiobjective models. Category A illustrates the efficient frontier for $0-1$ million people affected, category B between 1 million -2 million people, category $\mathrm{C}$ between 2 million -3 million people and category D between 3 million and 4 million people affected. The four categories are given in Figure 2, illustrating that with each category the number of aid supplies will increase, increasing the overall costs of a pre-positioning facility. The categories can be used as a decision tool to determine the quantities of supplies to be kept within an acceptable budget.

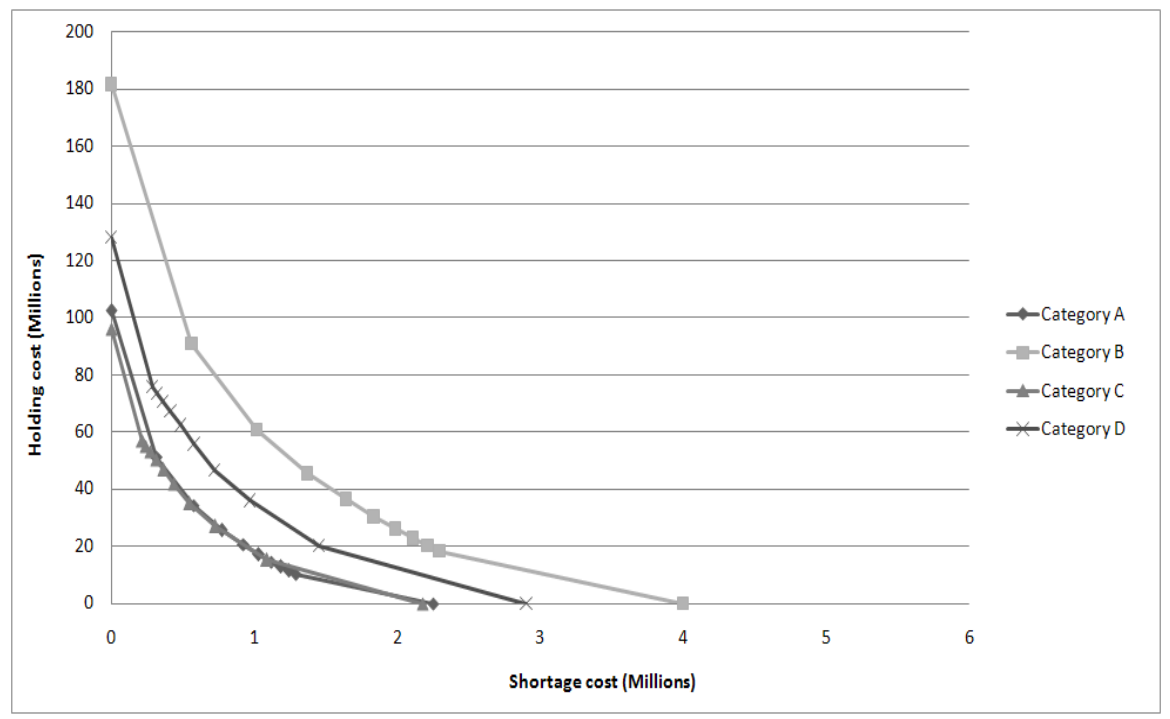

Fig. 2. Efficient frontier for each category

\section{$5 \quad$ Conclusion and Future Work}

The aim of this paper is to show how mathematical modeling can provide strategic decision support for selecting the required amount and types of aid supplies, and the most appropriate quantities of pre-positioning facilities within Somalia.

The models address the concerns of feasibility, consistency and completeness. From a decision-maker's point of view, the model can serve as a convenient guideline to assist with planning of types and quantities of aid supplies that should be kept for sufficient preparedness. The results of the model indicate that workable solutions have been identified, which have unveiled the possibility to increase the use of operational research methods to enhance disaster relief decision making.

Future research developments can complement this work by gathering data from other countries and applying the models to the pre-selected regions. It is also necessary to optimal man-power required during and after a disaster has occurred and finally, risk factors need to be incorporated as part of the formulation. 
In conclusion, this research challenges the fatal effects of disasters by providing instruments to overcome some of the difficulties of disaster management. Swani Vivekananda cautions [26]:

"If you think about disaster, you will get it. Brood about death and you hasten your demise.

Think positively and masterfully, with confidence and faith, and life becomes more secure, more fraught with action, richer in achievement and experience."

Disasters cause a great deal of suffering, but through careful planning, evaluation and the implementation of ongoing research, it is possible to achieve the aim of improving disaster preparedness through keeping sufficient amount of aid supplies in prepositioned facilities in Somalia, at reasonable and affordable cost structures.

Acknowledgments. The authors thank the National Research Foundation and the University of Pretoria for the financial support.

\section{References}

[1] News 24. More weather extremes expected (2011), http: / / m. news . 24 . com/ (accessed November 13, 2011)

[2] Tomasini, R., Wassenhove, L.: Humanitarian Logistics. Palgrave Macmillan, U.K. (2009)

[3] Ciottone, G.R.: Disaster Medicine, 3rd edn. Elsevier Mosby, U.S.A. (2006)

[4] Arminas, D.: Supply lessons of tsunami aid. Supply Management. The Purchasing and Supply Website 10(2), 14 (2005)

[5] Whybark, D.: Issues in managing disaster relief inventories. International Journal of Production Economics 108, 228-235 (2007)

[6] Bureau of African Affairs. U.S. Department of State, Somalia (2012), http: / / www. state.gov/r/pa/ei/bgn/2863.htm (accessed February 10, 2012)

[7] Blecken, A., Danne, C., Dangelmaier, W., Rottkemper, B., Hellinggrath, B.: Optimal Stock Relocation under Uncertainty in Post-disaster Humanitarian Operations. In: Proceedings of the 43rd Hawaii International Conference on System Sciences, pp. 1-10. IEEE Computer Society Press (2010)

[8] Altay, N., Green, W.G.: OR/MS research in disaster operations management. European Journal of Operations Research 175, 475-493 (2006)

[9] Hills, A.: Seduced by recovery: The consequences of misunderstanding disaster. Journal of Contingencies and Crises Management 6(3), 162-170 (1998)

[10] Rawls, C.G., Turnquist, M.A.: Pre-positioning of emergency supplies for disaster response. Transportation Research, Part B 44(4), 521-534 (2009)

[11] Duran, S., Gutierrez, M.A., Keskinocak, P.: Pre-positioning of Emergency Items Worldwide for CARE international. INFORMS (2009) doi: 10.1287

[12] Bryson, K.M.N., Millar, H., Joseph, A., Mobolurin, A.: Using formal MS/OR modeling to support disaster recovery planning. European Journal of Operations Research 141, 679-688 (2002)

[13] Van Wyk, E., Bean, W.L., Yadavalli, V.S.S.: Modelling of uncertainty in minimizing the cost of inventory for disaster relief. South African Journal of Industrial Engineering 22(1), 1-11 (2011a) 
[14] Mete, H.O., Zabinsky, Z.B.: Stochastic optimization of medical supply location and distribution in disaster management. International Journal of Production Economics 126, 76-84 (2009)

[15] Snyder, L.V.: Facility location under uncertainty: a review. IIE Transactions 38(7), 547564 (2006)

[16] Özdamar, L., Ekinci, E., Küçükyazici: Emergency logistics planning in natural disasters. Annals of Operations Research 129(1-4), 217-245 (2004)

[17] Beraldi, P., Bruni, M.E.: A probabilistic model applied to emergency service vehicle location. European Journal of Operations Research 196(1), 323-331 (2009)

[18] Beamon, B.M., Kotleba, S.: Inventory modeling for complex emergencies in humanitarian relief operations. International Journal of Logistics: Research and Applications 9(1), 1-18 (2006)

[19] Karlin, S., Fabens, A.: The (s,S) inventory model under Markovian demand process. Mathematical Methods in the Social Sciences, 159-175 (1960)

[20] Taskin, S., Lodree, E.: Inventory decisions for emergency supplies based on hurricane count predictions. International Journal of Production Economics, 1-10 (2009)

[21] Van Wyk, E., Yadavalli, V.S.S., Bean, W.L.: Strategic inventory management for disaster relief. Management Dynamics 20(1), 32-42 (2011b)

[22] Van Wyk, E., Yadavalli, V.S.S.: Application of an Euclidean distance algorithm for strategic inventory management for disaster relief in the SADC. In: Proceedings of the 41st International Conference on Computers \& Industrial Engineering, October 23-27, Los Angelas, pp. 894-899 (2011c)

[23] Rardin, R.: Optimization in Operations Research. Prentice Hall, Upper Saddle River (1998)

[24] CRED, Country Profiles (2009), http: / / www.emdat.be/disaster-profiles (accessed January 10, 2012)

[25] Winston, W.: Introduction to probability models, 4th edn. Curt Hinrichs (2004)

[26] Swani Vivekananda, Think Exist (2010), http: / / www . thinkexist.com/ (accessed March 22, 2010) 